\title{
Therapeutic Potential of Human Adipose- Derived Stem Cell Exosomes in Stress Urinary Incontinence - An in Vitro and in Vivo Study
}

\author{
Jianshu Nia Hongchao Lib Yiwen Zhouc Baojun Gu ${ }^{a} \quad$ Yuemin $\mathrm{Xu}^{\mathrm{a}}$

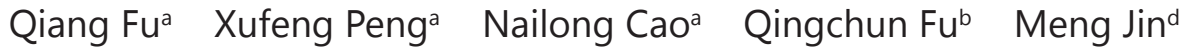 \\ Guangxi Sun $^{d}$ Jihong Wang ${ }^{a}$ Yinpeng Jin ${ }^{b}$ Feng Liu ${ }^{e}$
}

aDepartment of Urology, Shanghai Jiao Tong University Affiliated Sixth People's Hospital, Shanghai, bShanghai Public Health Clinical Center, Fudan University, Shanghai, 'Department of Plastic and Reconstruction Surgery, Shanghai Jiao Tong University School of Medicine Affiliated Ninth People's Hospital, Shanghai, 'Department of Urology and Institute of Urology, West China Hospital, Sichuan University, Chengdu, eDepartment of Urology, Fengxian Central Hospital of Shanghai, Shanghai, China

\section{Key Words}

Stress urinary incontinence $\cdot$ Adipose-derived stem cell $•$ Exosome $\cdot$ Therapy

\begin{abstract}
Background/Aims: To evaluate whether local injection of exosomes derived from human adipose-derived stem cells (hADSCs) facilitates recovery of stress urinary incontinence (SUI) in a rat model. Methods: For the in vitro study, a Cell Counting Kit-8 (CCK-8) array and proteomic analysis were performed. For the in vivo study, female rats were divided into four groups: sham, SUI, adipose-derived stem cell (ADSC), and exosomes ( $n=12$ each). The SUI model was generated by pudendal nerve transection and vaginal dilation. Vehicle, hADSCs, or exosomes were injected into the peripheral urethra. After 2, 4, and 8 weeks, the rats underwent cystometrography and leak point pressure (LPP) testing, and tissues were harvested for histochemical analyses. Results: The CCK-8 experiment demonstrated that ADSC-derived exosomes could enhance the growth of skeletal muscle and Schwann cell lines in a dosedependent manner. Proteomic analysis revealed that ADSC-derived exosomes contained various proteins of different signaling pathways. Some of these proteins are associated with the PI3K-Akt, Jak-STAT, and Wnt pathways, which are related to skeletal muscle and nerve regeneration and proliferation. In vivo experiments illustrated that rats of the exosome group had higher bladder capacity and LPP, and had more striated muscle fibers and peripheral nerve fibers in the urethra than rats of the SUI group. Both urethral function and histology of
\end{abstract}

J. Ni, H. Li and Y. Zhou contributed equally to this work.

\begin{tabular}{ll}
\hline Jihong Wang, Yinpeng Jin & Department of Urology, Shanghai Jiao Tong University Affiliated Sixth People's Hospital \\
and Feng Liu & Shanghai 200233 (China) \\
& E-Mail wangjihongsh@aliyun.com, 1182008211@qq.com, 13916672582@163.com
\end{tabular}


rats in the exosome group were slightly better than those in the ADSC group. Conclusions: Local injection of hADSC-derived exosomes improved functional and histological recovery after SUI.

\section{Introduction}

Stress urinary incontinence (SUI) is a common medical condition affecting approximately $30 \%$ of postpartum women and interfering with their quality of life $[1,2]$. It is defined as a "complaint of involuntary loss of urine upon effort or physical exertion (e.g., sporting activities), or sneezing or coughing" according to the International Continence Society (ICS) guidelines [3]. SUI results from a combination of intrinsic urethral sphincter deficiency and an anatomic defect in urethral support that leads to insufficient urethral closure pressure [4]. The mechanism of SUI is multifactorial and complex [5].

Several treatments for SUI are currently available, of which mid-urethral sling surgery is the most common and effective therapeutic method [6]. Despite the common use of midurethral sling surgery, this procedure is associated with a high level of complications, and therefore there is a need for new medical treatment options [7].

Stem cell-based therapy has gained attention as a promising treatment for SUI in recent years [6-8]. Among the different types of stem cells, adipose-derived stem cells (ADSCs) have been widely used since they can be easily and abundantly obtained and because of their multiple differentiation potential and low immunogenicity. Several studies have reported the efficacy of ADSCs in improving SUI in rats and humans [9-12]. However, the underlying mechanisms remain controversial. Recently, an increasing number of studies have demonstrated that a paracrine effect rather than stem cell differentiation is the main factor resulting in their therapeutic effect [13]. Meanwhile, the direct use of stem cells remains restricted by issues such as potential chromosomal variation, tumorigenicity, thrombosis, immunological rejection, and ethical limitations [14-16]. Hence, a superior cell-free approach that can exert the same therapeutic effects of stem cells and avoid their adverse events is anticipated.

Exosomes are 40- to 150-nm-sized nanoparticles originating from multivesicular bodies and are important paracrine effectors in intercellular communication. They function by transferring proteins and genetic materials to target cells [17]. It has been demonstrated that exosomes exhibit functional properties similar to those of the cells from which they are derived, and direct treatment with these nanoparticles has no apparent adverse effects such as immunogenicity, tumorigenicity, or vascular obstruction $[18,19]$. Recent studies have reported that exosomes secreted by ADSCs show potential in tissue regeneration and protection, including bone, muscle, skin, and brain tissue [20-23]. Thus far, there have been no studies to our knowledge on the application of exosomes released by stem cells in SUI therapy. We hypothesized that ADSC-derived exosomes could be effective in treating SUI by promoting tissue regeneration after injury.

In the present study, we used human ADSCs (hADSCs) as the origin of exosomes and investigated whether the early administration of these exosomes could treat SUI in both in vitro and in vivo studies.

\section{Materials and Methods}

Isolation and culture of hADSCs

hADSCs were isolated from the musculocutaneous flap of a patient as described previously [24], with patient consent in accordance with procedures approved by the Medical Ethics Committee of Shanghai Jiao Tong University Affiliated Sixth People's Hospital (approval number 2017-004). Briefly, the fresh fat specimen was washed with phosphate-buffered saline (PBS) and chopped using sterile surgical scissors. The chopped tissues were digested with $0.2 \%$ collagenase type I (Gibco, Thermo Fisher Scientific, Waltham, 
MA, USA) at $37^{\circ} \mathrm{C}$ for $1.5 \mathrm{~h}$. The suspension was neutralized with isometric culture media and centrifuged at $1500 \mathrm{rpm}$ for $5 \mathrm{~min}$. The cell pellet was then resuspended in Dulbecco's modified Eagle's medium/F12 (DMEM/F12) (Gibco) supplemented with 10\% fetal bovine serum (Gibco). The cells were plated at a density of $10^{6}$ cells $/ \mathrm{ml}$ and then maintained at $37^{\circ} \mathrm{C}$ in a humidified incubator supplemented with $5 \% \mathrm{CO}_{2}$, and the medium was changed every other day. The hADSCs at passage 4 were used for the subsequent experiments.

\section{Characterization of hADSCs}

The culture-expanded hADSCs were tested for their ability to differentiate into adipocytes and osteoblasts. Passage $4 \mathrm{hADSCs}$ at a density of $5 \times 10^{3}$ cells $/ \mathrm{cm}^{2}$ were seeded into 6-well plates precoated with a cover glass and induced for 3 weeks with adipogenic (HUXMA-90031, Cyagen Biosciences, Inc., Guangzhou, China) or osteogenic (HUXMA-90021, Cyagen Biosciences Inc.) differentiation media. The cells were then fixed in $10 \%$ formalin and stained with Oil Red 0 or Alizarin red in accordance with the manufacturer's protocol (Cyagen Biosciences, Inc.). Stained cells were washed 3 times with PBS and detected using microscopy (Olympus, Tokyo, Japan).

To observe the phenotypes, flow cytometry was used simultaneously. Passage 4 hADSCs were used to prepare a single-cell suspension, and subsequently $2 \mu \mathrm{l}$ of CD90-FITC, CD44-PE, CD73-APC, or CD105PerCP-CP5.5 antibodies were added to the suspension. These cell aliquots were incubated for 30 min on ice protected from light, washed 3 times, and then detected by flow cytometry (BD FACSAria III; BD Biosciences, San Jose, CA, USA).

\section{Isolation of hADSC exosomes}

Exosomes were isolated from ADSC supernatants by our novel ultrafiltration method, as previously described [25], and cultured in DMEM/F12 medium. After hADSCs reached 80\% confluence, the conditioned medium was collected and filtered through a $0.22-\mu \mathrm{m}$ Sterilize Steritop filter (Millipore, Burlington, MA, USA). Then, the conditioned medium was transferred to a $15-\mathrm{ml} 100-\mathrm{kDa}$ Amicon Ultra Centrifugal filter and centrifuged at $4000 \times g$ for $40 \mathrm{~min}$ at $4^{\circ} \mathrm{C}$. The supernatants were then transferred to a $500-\mu \mathrm{l}$ Amicon Ultra Centrifugal filter and ultracentrifuged at $14,000 \times g$ for $10 \mathrm{~min}$. Then, the ultrafiltration liquid was resuspended in $450 \mu \mathrm{l}$ PBS and ultrafiltrated again at $14,000 \times g$ for $10 \mathrm{~min}$. Finally, the ultrafiltration liquid was centrifuged at $1000 \times g$ for 2 min to collect concentrated exosomes. Exosomes were stored in aliquots at $-80^{\circ} \mathrm{C}$ or used for other downstream experiments. An equal volume of DMEM/F12 was obtained in the same procedure as the collection of exosomes for control medium.

\section{Characterization of hADSC exosomes}

The isolated exosomes were characterized morphologically by dynamic light scattering (DLS), scanning electron microscopy (SEM), and antibody array for the expression of surface markers. DLS measurements were performed by a Zetasizer Nano ZS90 (Malvern, Worcestershire, UK). The size distribution plot with an $x$ axis showing the distribution of estimated particle radius $(\mathrm{nm})$ and a $y$ axis showing the relative intensity of the scattered light was analyzed with NS300 software. For SEM examination, the sample exosomes were fixed in $0.5 \%$ glutaraldehyde solution overnight and then dehydrated in absolute ethanol for $10 \mathrm{~min}$ and collected on formvar grids stabilized with carbon (TED PELLA, Inc., Redding, CA, USA). The grids were contrasted with $1 \%$ phosphotungstic acid for $1 \mathrm{~min}$ and then examined using a field-emission electron microscope (JEOL Ltd., Tokyo, Japan). Exosomal markers were detected using an Exo-Check antibody array pre-printed with 8 antibodies for exosomal markers (FLOT-1, ICAM, ALIX, CD81, CD63, EpCAM, ANXA5, and TSG101) (System Biosciences, Mountain View, CA, USA). Briefly, $300 \mu \mathrm{g}$ of total protein extracted from exosomes was incubated with membrane overnight at $4^{\circ} \mathrm{C}$. After washing, the labeled proteins were visualized with the ChemiDoc XRS imaging system (Bio-Rad Laboratories, Inc., Hercules, CA, USA).

\section{Cell proliferation analysis}

Cell proliferation was evaluated by the Cell Counting Kit-8 assay (CCK-8, Dojindo, Kumamoto, Japan). L6 rat skeletal muscle cells and RSC96 rat schwann cells, obtained from the cell bank of the Chinese Academy of Science (Shanghai, China), were seeded into a 96-well plate at a density of $4 \times 10^{3}$ cells per well and allowed to attach for $4 \mathrm{~h}$. Then, to each well was added control culture medium and culture medium containing different concentrations of exosomes $(0.05,0.5$, and $5 \mu \mathrm{g} / \mathrm{ml})$. The concentration of the exosomes was

\section{KARGER}




\section{Cellular Physiology Cell Physiol Biochem 2018;48:1710-1722 \begin{tabular}{l|l} 
and Biochemistry Published online: August 2, 2018 & $\begin{array}{l}\text { C) } 2018 \text { The Author(s). Published by S. Karger AG, Basel } \\
\text { www.karger.com/cpb }\end{array}$ \\
\hline
\end{tabular}}

$\mathrm{Ni}$ et al.: Therapeutic Potential of ADSC Exosomes in SUI

measured using a BCA Protein Assay Kit (Beyotime, Nantong, China). At 2, 24, 48, and 72 h, CCK-8 agent (10 $\mu \mathrm{l}$ per well) was added to cells, followed by incubation at $37^{\circ} \mathrm{C}$ for $2 \mathrm{~h}$. The growth curves were generated using absorbance values at $450 \mathrm{~nm}(n=6)$ detected with a microplate reader (Bio-Rad).

\section{Proteomic analysis of hADSC exosomes}

For proteomic analysis, the collected exosomes were digested at $4^{\circ} \mathrm{C}$ for $20 \mathrm{~h}$ with $0.25 \%$ trypsin (proteomics grade, Sigma-Aldrich, St. Louis, MO, USA). The digestion was quenched by adding $2 \mu \mathrm{l}$ formic acid $\left(30 \mathrm{~min}\right.$ at $\left.37^{\circ} \mathrm{C}\right)$, centrifuged at $17,000 \times \mathrm{g}$ for $10 \mathrm{~min}$, and then transferred into the micro-vial for analysis.

Mass spectrometric measurements were performed using a high-performance liquid chromatography system with a Q-Exactive mass spectrometer equipped with an Easy-nLC (Thermo Fisher Scientific). Ten microliters of deglycosylated peptides was loaded onto an EASY-Column (Thermo Fisher Scientific, 0.075 $\mathrm{mm} \times 100 \mathrm{~mm}, 3-\mu \mathrm{m}$ particle size), and separation was performed at a flow rate of $250 \mathrm{nl} / \mathrm{min}$ using a gradient constructed from solution A ( $2 \%$ acetonitrile, $0.1 \%$ formic acid) and solution B ( $84 \%$ acetonitrile, $0.1 \%$ formic acid): $4-50 \%$ B for $50 \mathrm{~min} ; 50-100 \%$ B for $4 \mathrm{~min}$; and $100 \%$ B for $6 \mathrm{~min}$. The mass/charge ratio was determined after full scan.

For peptide identification, all the spectra were analyzed with Proteome Discoverer (version 1.4.0.29, Thermo Fisher Scientific). For database searching, the Mascot search engine (version 2.3.02, Matrix Science, London, UK) was used to search against the appropriate database. Non-intact ( $>20 \mathrm{ppm})$ peptides and fragmented ions (0.6 Da) were removed, with allowance for one missed cleavage in trypsin digests. For the study of the biological functions of identified proteins, a Gene Ontology (G0) analysis was performed using GoMiner software (available at http://discover.nci. nih.gov/gominer/). To reveal which pathways were significantly represented by the identified proteins, pathway analysis was performed using the Kyoto Encyclopedia of Genes and Genomes (KEGG) database (available at http://www.genome.jp/kegg/pathway. html).

\section{Animal experiment design}

This study was approved by the Institutional Animal Care and Use Committee of the Shanghai Jiao Tong University Affiliated Sixth People's Hospital. Forty-eight adult female Sprague-Dawley rats (250-300 g) were randomly divided into four groups: sham, SUI, SUI+ADSCs, and SUI+Exosomes. The sham group underwent sham injury with $50 \mu \mathrm{l}$ saline injected into the peripheral urethra. The SUI group underwent pudendal nerve transection (PNT) and vaginal dilation (VD) with $50 \mu$ l saline injected into the peripheral urethra. The SUI+ADSCs group underwent PNT+VD with 2 million ADSCs suspended in $50 \mu$ l saline injected into the peripheral urethra. The SUI+ADSCs group underwent PNT+VD with $50 \mu \mathrm{g}$ exosomes suspended in $50 \mu \mathrm{l}$ saline injected into the peripheral urethra. All treatments were administered $1 \mathrm{~h}$ after the end of PNT+VD. Four rats in each group underwent continuous cystometrography (CMG) and leak point pressure (LPP) testing and were then euthanized for anatomic assessment of the urethra at 2, 4, and 8 weeks after injury.

\section{PNT and VD}

Rats were anesthetized with $2 \%$ isoflurane and underwent PNT and VD according to the following procedure. The pudendal nerve (Fig. 1A) was isolated bilaterally and transected. A modified $10 \mathrm{~F}$ Foley catheter (Fig. 1B) was inserted into the vagina, and the balloon was inflated with $3 \mathrm{ml}$ water for $4 \mathrm{~h}$. A sham injury was created by making an incision in the dorsal skin and inserting the Foley catheter for $4 \mathrm{~h}$ without inflation. Buprenorphine $(0.1 \mathrm{mg} / \mathrm{kg})$ was administered subcutaneously twice daily after PNT+VD or sham injury for 2 days for analgesia.

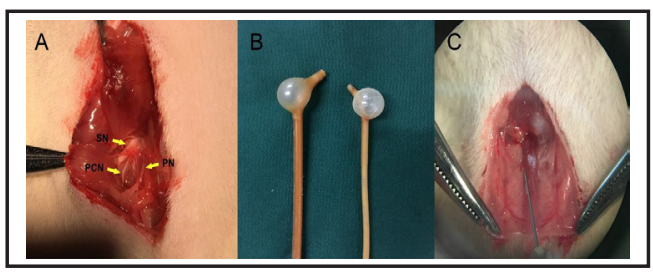

Fig. 1. Images of animal experiments. A: Anatomical labels show sciatic nerve, posterior cutaneous nerve, and pudendal nerve. B: Different sizes of urethral dilators. C: Midurethra was detected after a lower abdominal incision. 


\section{Cellular Physiology Cell Physiol Biochem 2018;48:1710-1722 \\ \begin{tabular}{l|l} 
and Biochemistry Published online: August 2, 2018 & $\begin{array}{l}\text { C) } 2018 \text { The Author(s). Published by S. Karger AG, Basel } \\
\text { www.karger.com/cpb }\end{array}$ \\
\hline
\end{tabular}}

$\mathrm{Ni}$ et al.: Therapeutic Potential of ADSC Exosomes in SUI

\section{Peripheral urethra injection}

One hour after the end of VD or sham VD, a lower cut was made, and the mid-urethra was exposed. Saline, ADSCs, or exosomes were injected into the peripheral urethra using a Hamilton microinjector (Fig. 1C).

CMG and LPP test

CMG and LPP were recorded simultaneously by an investigator blinded to the experimental group. Under urethane anesthesia ( $1.2 \mathrm{~g} / \mathrm{kg}$, intraperitoneal), a transvesical catheter was inserted into the bladder dome and fixed with a suture. The abdominal wall was closed, and the catheter was connected to a pressure transducer (MLT0380/D, AD Instruments Pty, Ltd., Sydney, Australia) and a syringe pump (WZ50CZ, Smiths Medical Instrument Zhejiang Co.,ltd, China) to fill the bladder (6 ml/h). The bladder was filled for three to four voiding cycles, and the mean filling time was calculated as the interval between the end of each void and the beginning of next void. The continuous CMG was recorded, and the bladder capacity (BC) was calculated. The bladder was then manually emptied and refilled until approximately half mean filling time, when a slowly increasing external pressure was applied directly to the bladder using a cotton-tipped swap. This externally applied pressure was rapidly removed at the first sign of leakage at the urethral meatus. It has been previously shown that LPP is not highly sensitive to bladder volume in rats, except at very low volumes [26]. Therefore, this estimate of half capacity was sufficient to ensure consistent results. This LPP test was repeated three to four times in each rat. LPP was calculated by subtracting baseline bladder pressure from peak bladder pressure during LPP testing.

\section{Histology}

To assess anatomical recovery of the urethra, the urethra was harvested en bloc with the anterior vagina 2, 4, or 8 weeks after injury and paraformaldehyde fixed, paraffin embedded, transversely sectioned (5 $\mu \mathrm{m})$, and stained with hematoxylin \& eosin (HE) or Masson. For image analysis, 5 randomly selected sections per animal were photographed using NIS-Elements D 3.10 software (Nikon). The proportion of striated muscle in the urethra was quantified (20× magnification).

\section{Immunofluorescent staining}

To investigate the effects of each treatment, the urethral sections were stained with anti-fast myosin skeletal heavy chain (anti-FMHC) rat polyclonal antibody (1:200, ab91506, Abcam, Cambridge, UK) and anti-neurofilament 200 mouse monoclonal antibody (1:100, N0142, Sigma-Aldrich) followed by Cy3donkey anti-goat secondary antibody (1:300, No. GB21404, Servicebio, Wuhan, China) and FITC-donkey anti-rabbit secondary antibody (1:200, No. GB22403, Servicebio). Slides were coverslipped with mounting medium containing 4',6-diamidino-2-phenylindole (Vector Laboratories, Southfield, MI, USA) and imaged on a confocal microscope. For determining the mean intensity of FMHC and neurofilament 200 immunofluorescence, 5 random sections per animal were observed and analyzed using ImageJ software (NIH, USA).

\section{Statistical analysis}

Numerical data are presented as mean \pm the standard deviation. All statistical analyses in this study were performed using SPSS 16.0 software (IBM Corp., Armonk, NY, USA). The significance of differences between two groups was analyzed by one-way analysis of variance (ANOVA) with the Tukey honest significant difference test for post hoc analysis, or the paired-samples $t$ test, as appropriate. A $P$ value $<0.05$ was considered significant.

\section{Results}

\section{Isolation and characterization of hADSCs}

After four passages in culture, the expanded hADSC population became homogeneous, showing a monolayer of adherent cells and demonstrating a typical fibroblast-like and shuttle-shaped morphology (Fig. 2A). To characterize the phenotype of hADSCs, flow cytometric analysis was performed. The results revealed that more than $90 \%$ of the cells 
Fig. 2. Characterization of human adipose-derived stem cells (hADSCs). A: Morphology of P0 and P5 hADSCs. B: Flow cytometry revealed that more than $90 \%$ of the cells strongly expressed surface antigens, such as CD90 (99.8\%), CD44 (100\%), CD105 (97.6\%), and CD73 (97.1\%) but were virtually negative for CD34, CD45, CD11b, CD19, and HLA-DR (all <3\%). C: Differentiation assays revealed that ADSCs could differentiate into adipocytes and osteocytes, which were stained by Oil Red 0 and Alizarin red, respectively.

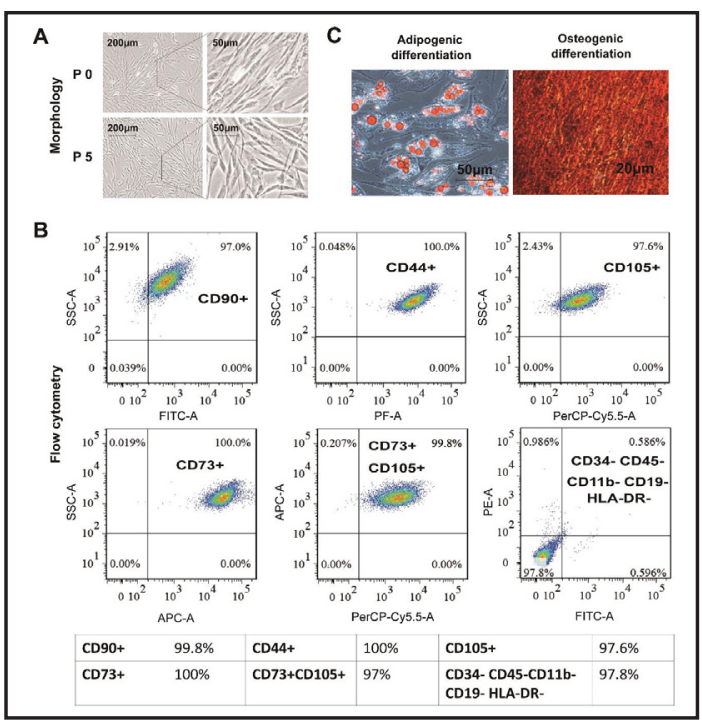

strongly expressed surface antigens such as CD90 (99.8\%), CD44 (100\%), CD105 (97.6\%), and CD73 $(97.1 \%)$ but were virtually negative for CD34, CD45, CD11b, CD19, and HLA-DR (all <3\%) (Fig. 2B). To definitively characterize the multipotency of these hADSCs, adipogenic differentiation and osteogenic differentiation were performed. After culture in adipogenic induction media for 3 weeks, more than $80 \%$ of the cells differentiated into adipocytes that could be stained with Oil Red 0. Similarly, after osteogenic induction, more than $70 \%$ of the cells differentiated into osteoblasts, as demonstrated by Alizarin red staining (Fig. 2C). The results indicated that the multipotency of cultured hADSCs was well maintained.

\section{Isolation and identification of exosomes derived from $h A D S C S$}

DLS, SEM, and antibody array were used to characterize the particles secreted from ADSCs. The size profiles of exosomes were evaluated by NanoSight technology and SEM imaging. The results showed that most of these vesicles ranged from 30 to $150 \mathrm{~nm}$ in size (Fig. 3A, 3B). Brownian activity of these particles was recorded as Video S1. For all supplemental material see www.karger.com/ doi/10.1159/000492298. We detected the surface markers of exosomes using the antibody array method, and observed that markers such as FLOT1, ICAM, ALIX, TSG101, ANXA5, EpCAM, CD63, and CD81 were positively expressed (Fig. 3C).

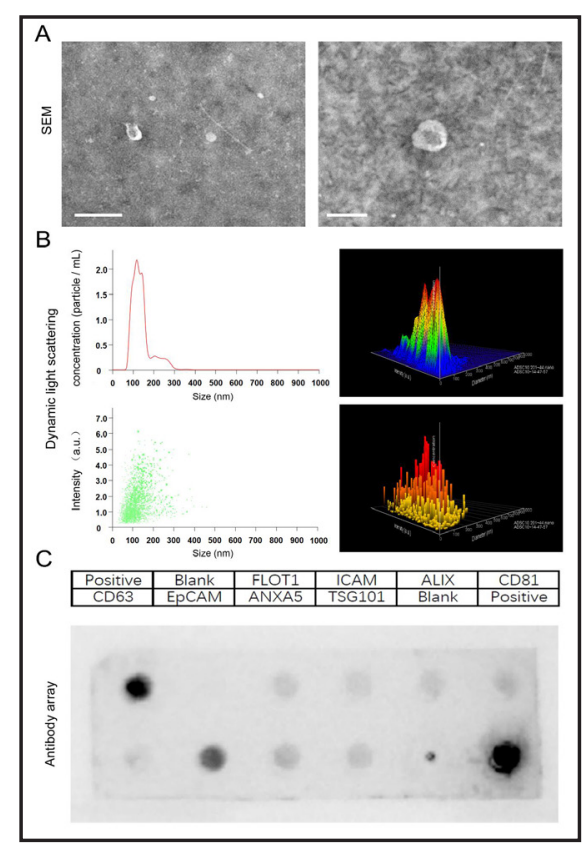

Fig. 3. Characterization of human adiposederived stem cell exosomes. A: Under scanning electron microscopy (SEM), exosomes appear with a round shape and are approximately 30 to 150 nanometers in size. B: Dynamic light scattering also showed that most of these vesicles ranged from 30 to $150 \mathrm{~nm}$ in size. C: We detected the surface markers of exosomes using an antibody array method, and observed that markers such as FLOT1, ICAM, ALIX, TSG101, ANXA5, EpCAM, CD63, and CD81 are positively expressed. 
Fig. 4. CCK-8 assay. Both cell lines treated with exosomes showed a significant increase in proliferation in a dose-dependent manner as compared with those treated with conditioned medium at day $3(72 \mathrm{~h}) .{ }^{*} \mathrm{P}<0.05$.

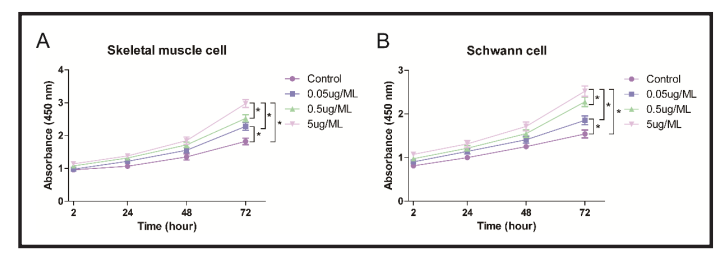

Fig. 5. Proteomic analysis of human adipose-derived stem cell (hADSC) exosomes. A: Gene Ontology (GO) analysis of three ontologies (biological process, molecular function, and cellular components). The bar graph shows the relationship between each the three ontologies and the number and amount (percentage) of the proteins. The $\mathrm{x}$ axis represents the three ontologies, the left $\mathrm{y}$ axis represents the number of proteins, and the right $y$ axis represents the percentage of the proteins. B: The proteins carried by the hADSC exosomes are involved in many different important biological processes. The FASTA protein sequences of differentially changed proteins were blasted against the online Kyoto Encyclopedia of Genes and Genomes (KEGG) database (http://geneontology.org/), and were subsequently mapped to processes in KEGG. In $A$ and B, GO and KEGG pathway enrichment analyses were applied based on Fisher's exact test, considering the whole quantified protein/phosphor proteins annotation as the background dataset. Benjamini-Hochberg correction for multiple testing was further applied to adjust derived $P$ values, and only functional categories and pathways with $P$ values under a threshold of 0.05 were considered

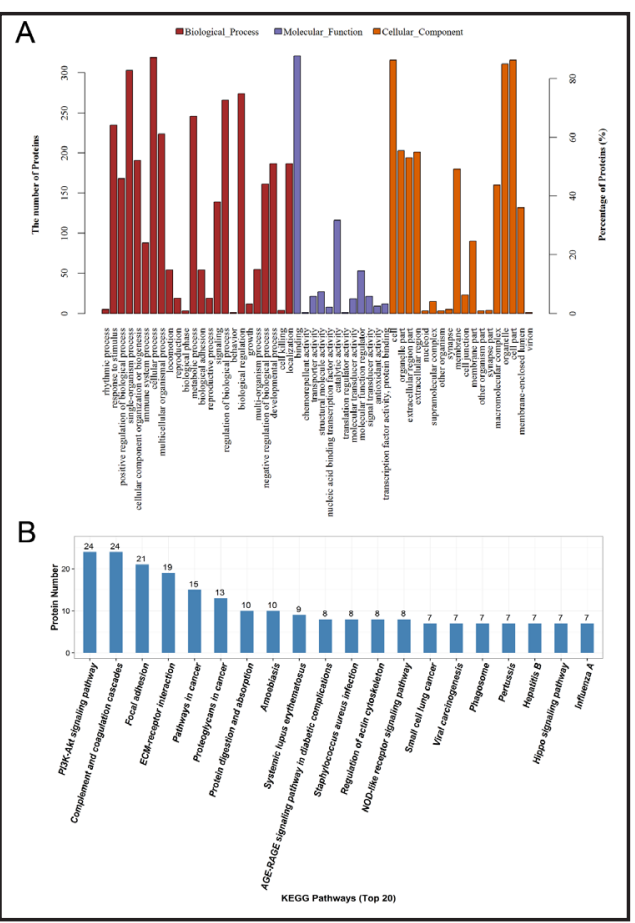
significant.

\section{Exosomes derived from ADSCs induced proliferation}

To explore whether ADSC-derived exosomes could induce the regeneration of skeletal muscle and nerve fibers, both skeletal muscle cells and glial cells were incubated with control medium or medium containing exosomes at three different concentrations $(0.05,0.5$, and 5 $\mu \mathrm{g} / \mathrm{ml}$ ) for $72 \mathrm{~h}$. Both cell lines treated with exosomes, as measured by the CCK-8 assay, exhibited significantly increased proliferation in a dose-dependent manner as compared with cells treated with control medium at day 3 (Fig. 4A, 4B).

\section{Proteomic analysis of hADSC exosomes}

Proteomic analysis of the exosomes identified 1, 466 proteins that are implicated in various cell functions and pathways.

\section{Gene Ontology (GO) analysis}

To obtain a functional overview of hADSC exosome proteins, we further analyzed the exosome proteome using the GoMiner program by searching against GO databases (January 2008 version). The results showed that 331 proteins mapped to specific biological processes, 341 were associated with diverse cellular components, and 336 had other molecular functions. The resulting graph shows the relationship between each of the three ontologies and the number and amount (percentage) of the associated proteins (Fig. 5A). 
Table 1. Proteins of related signaling pathways

KEGG pathway
analysis
KEGG pathway

analysis (September 2007 version) was performed on the identified exosome proteins to evaluate which pathways were significantly represented. The results showed that two hundred twenty-two different pathways were linked to the exosomes. The top 20 KEGG pathways are shown in Fig. 5B, and proteins of pathways related to muscle and nerve regeneration and proliferation, including PI3K-Akt, Jak-STAT, and Wnt, are shown in Table 1.

\section{Assessment of urethral function}

Functional evaluation of the urethra was assessed through CMG and LPP testing at 2, 4, and 8 weeks after injection. In the sham group, BCs were $0.525 \pm 0.065 \mathrm{ml}, 0.533 \pm 0.043 \mathrm{ml}$, and $0.535 \pm 0.044 \mathrm{ml}$ respectively, while LPPs were $47.25 \pm 2.22 \mathrm{cmH}_{2} \mathrm{O}, 46.25 \pm 2.21 \mathrm{cmH}_{2} \mathrm{O}$, and 47.5 $\pm 2.65 \mathrm{cmH}_{2} \mathrm{O}$, respectively. In the SUI group, BCs were $0.275 \pm 0.065 \mathrm{ml}, 0.28 \pm 0.044 \mathrm{ml}$, and 0.27 $\pm 0.026 \mathrm{ml}$, respectively, while LPPs were 22.75 $\pm 2.23 \mathrm{cmH}_{2} \mathrm{O}, 23.25 \pm 2.20 \mathrm{cmH}_{2} \mathrm{O}$, and $25.25 \pm$ $2.5 \mathrm{cmH}_{2} \mathrm{O}$, respectively. In the ADSC group, BCs were $0.4 \pm 0.044 \mathrm{ml}, 0.438 \pm 0.035 \mathrm{ml}$, and 0.455 $\pm 0.034 \mathrm{ml}$, respectively, while LPPs were $32.5 \pm$ $2.08 \mathrm{cmH}_{2} \mathrm{O}, 35.75 \pm 1.71 \mathrm{cmH}_{2} \mathrm{O}$, and $41.25 \pm 1.71$ $\mathrm{cmH}_{2} \mathrm{O}$, respectively. In the exosome group, $\mathrm{BCs}$ were $0.413 \pm 0.03 \mathrm{ml}, 0.455 \pm 0.045 \mathrm{ml}$, and 0.478 $\pm 0.054 \mathrm{ml}$, respectively, while LPPs were $34.5 \pm 2.1$ $\mathrm{cmH}_{2} \mathrm{O}, 37.5 \pm 2.08 \mathrm{cmH}_{2} \mathrm{O}$, and $42.8 \pm 2.22 \mathrm{cmH}_{2} \mathrm{O}$, respectively.

In the sham and SUI groups, BC and LPP remained stable at 2, 4, and 8 weeks after injection. In the ADSC and exosome groups, the BC and LPP values increased gradually at 2, 4, and 8 weeks after injection. At each time point, BCs and LPPs of both groups were significantly different compared with the SUI group $(P<0.05)$, and there was no statistically significant difference between the two groups (Fig. 6).

\section{Histological changes in the urethra}

The proportion of striated muscle in the urethra in each group was quantified to show the histological change in the urethras. In the sham group, the proportion of striated muscle was $0.304 \pm 0.009$ at 2 weeks, $0.301 \pm 0.012$ at 4 weeks, and $0.312 \pm 0.01$ at 8 weeks. In the SUI group, the proportion of striated muscle was $0.151 \pm 0.01$ at 2 weeks, $0.155 \pm 0.008$ at 4 weeks, and $0.157 \pm 0.006$ at 8 weeks. In the ADSC group, the proportion of striated muscle was $0.177 \pm 0.007$ at 2 weeks, $0.221 \pm 0.012$ at 4 weeks, and $0.248 \pm 0.01$ at 8 weeks. In the exosome group, the proportion of striated muscle was $0.181 \pm 0.009$ at 2 weeks, $0.225 \pm$ 0.012 at 4 weeks, and $0.261 \pm 0.01$ at 8 weeks.

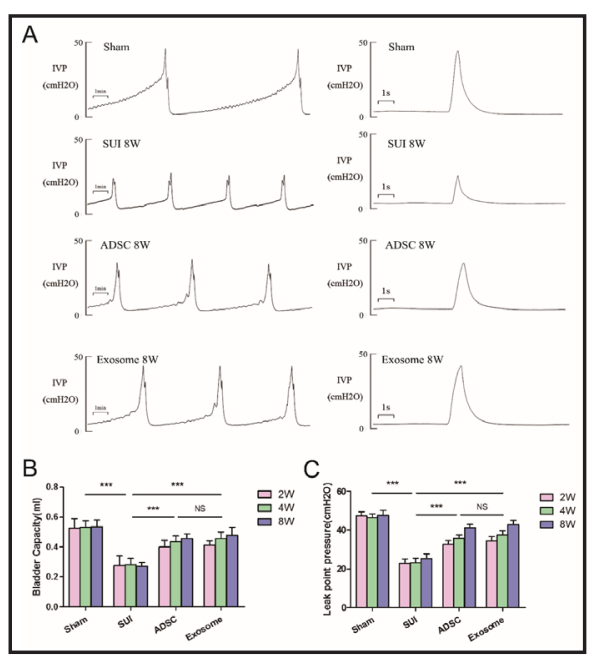

Fig. 6. Assessment of urethral function. A: Cystometrography (left) and leak point C: The bladder capacity and LPP of each group at 2, 4, and 8 weeks after injection. ${ }_{* * *} \mathrm{P}<0.01$. IVP, intravesical pressure; NS, non-significance. 


\section{Cellular Physiology and Biochemistry}

Cell Physiol Biochem 2018;48:1710-1722

\begin{tabular}{l|l}
\hline DOI: $10.1159 / 000492298$ & (c) 2018 The Author(s). Published by S. Karger AG, Basel
\end{tabular}

Ni et al.: Therapeutic Potential of ADSC Exosomes in SUI
Because of the sphincter striated muscle degeneration and atrophy, the proportion of striated muscle in the urethra of the SUI group was significantly decreased compared to that in the sham group (Fig. 7). In the ADSC and exosome groups, the proportion of striated muscle increased continuously at 2, 4, and 8 weeks after injection. At each time point, the proportion of striated muscle of both groups was significantly different compared with the SUI group $(P<0.05)$, and there was no statistically significant difference between the two groups (Fig. 7).

Results of HE staining (Fig. 8) showed no marked difference in inflammatory cells around the injection site after 8-week hADSC and exosome injections compared with the sham group, which indicated that no detectable immune response was induced.

Immunofluorescent staining of urethra

Striated muscle was FMHC positive and stained red, while peripheral nerves located outside the striated muscle layers were neurofilament 200 positive and stained green (Fig. 9). Eight weeks after injection, striated muscle and peripheral nerves of SUI rats were significantly fewer than those of the sham group. In contrast, the ADSC and exosome groups showed similar amounts of striated muscle and peripheral nerves compared to the sham group, and the difference was insignificant.

Fig. 7. Histological changes in the urethra. A: Masson's trichrome staining of midurethra of all groups at each time point. B: The proportion of striated muscle in the urethra in each group was quantified to show the histological change in the urethras. Scale bar $=100$ $\mu \mathrm{m} . \quad * * * \mathrm{P}<0.01$. NS, nonsignificance.

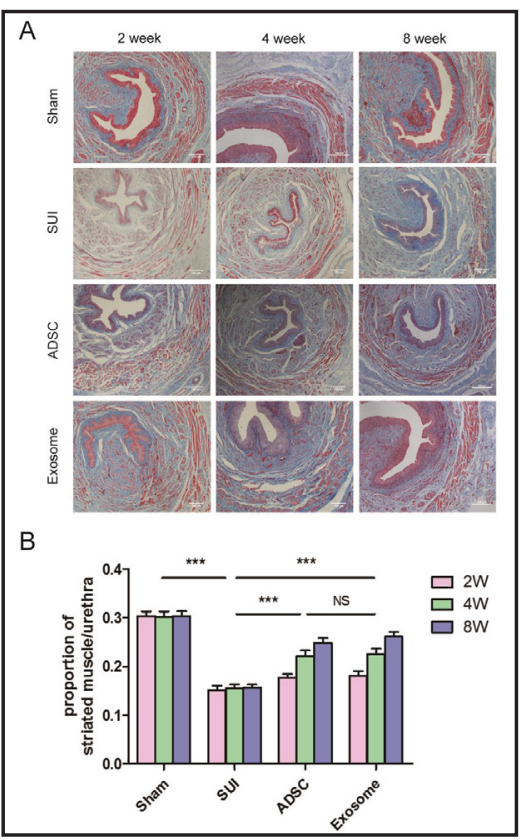

Fig. 8. HE staining of midurethra 8 weeks after injection showed no detectable increase in inflammatory cells around the injection site in the ADSC and exosome groups compared with sham. The results indicated that no significant immune response was induced. Scale bar $=100 \mu \mathrm{m}$.

Fig. 9. Immunofluorescent staining of urethra at 8 weeks after injection. Striated muscle was fast myosin heavy chain (FMHC) positive and stained red, while peripheral nerves located outside of the striated muscle layers were neurofilament 200 positive and stained green. Bar graphs showing the mean immunofluorescence intensity of FMHC and neurofilament 200 of 4 groups. Scale bar $=100 \mu \mathrm{m}$. *** $\mathrm{P}<0.01$. NS, non-significance.
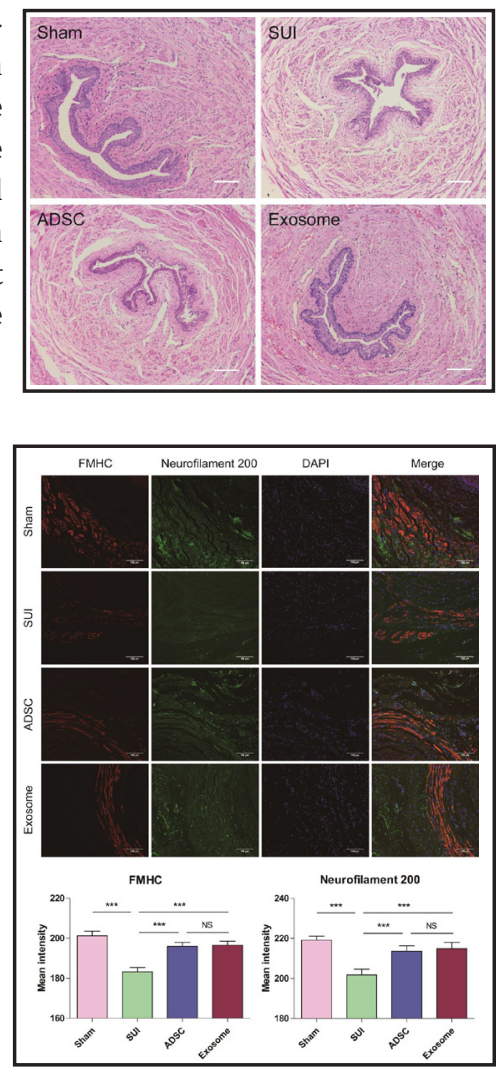


\section{Cellular Physiology Cell Physiol Biochem 2018;48:1710-1722 \\ \begin{tabular}{cc|c} 
DOI: 10.1159/000492298 & Cond Biochemistry & 2018 The Author(s). Published by S. Karger AG, Basel \\
www.karger.com/cpb
\end{tabular}}

$\mathrm{Ni}$ et al.: Therapeutic Potential of ADSC Exosomes in SUI

\section{Discussion}

Animal models have been used to better understand the mechanisms underlying, and find a potential treatment for SUI. Bilateral PNT produces denervation of the external urethra sphincter (EUS) and significantly decreases LPP, EUS electromyogram, and striated muscle [27]. This model offers the advantage that it may be representative of neurogenic damage that occurs in radical prostate surgery or urethral denervation and/or pudendal nerve and muscular damage that probably occurs during vaginal delivery [28, 29]. VD, another common model, damages the muscular and neurologic structures that maintain urinary continence [30]. The main limitation of this model is the short durability of the functional aspect, with a recovery within 6 weeks in most cases [31]. In the current study, we expanded the investigation to a complex dual-injury model, which represents both neurogenic and myogenic injuries and could last for months. This model enabled studying the long-term effects of exosomes on either tissue simultaneously.

It is generally accepted that skeletal muscle and peripheral nerve tissue have a low capacity to regenerate once injured. Various approaches using cellular and biochemical components have been explored in vitro and in vivo to enhance the regenerative capacity of injured skeletal muscle and peripheral nerves. Among them, stem cell-based therapies have clear beneficial effects on skeletal muscle and peripheral nerve repair [32, 33]. Although the mechanisms by which stem cell therapy act are still unknown, recent evidence has suggested they might be related to long-distance cell-to-cell communication via secreted paracrine factors in the extracellular environment [34]. Recent studies have shown the therapeutic potential of exosomes derived from various cells with secretory capacity (e.g., stem cells and progenitor cells) in various injured tissues [35, 36], including skeletal muscle and peripheral nerves $[37,38]$. Based on these considerations, the aim of this study was to investigate whether exosomes can be considered as effectors of ADSC functions in treating SUI and to identify their related molecular mechanisms.

In line with our hypothesis, our data showed that ADSCs exert their restorative properties via a paracrine mechanism that utilizes exosomes rather than by direct cellular interaction. The CCK-8 experiment demonstrated that ADSC-derived exosomes could enhance the growth of skeletal muscle and Schwann cell lines in a dose-dependent fashion. We found that the exosomes at $5 \mu \mathrm{g} / \mathrm{ml}$ have the strongest proliferation effect on both cell lines, and thus we used this concentration for in vivo study. In vivo experiments showed that ADSC-derived exosomes could improve urethral function and histology after SUI and performed slightly better than ADSCs. CMG and LPP tests demonstrated that both exosomes and ADSCs could accelerate the recovery of urethral function after SUI. Rats in both groups showed significantly higher BC and LPP compared with SUI rats. Moreover, we found that the restorative effects of exosomes and ADSCs were constant and could last for 8 weeks because the BC and LPP kept increasing over time. The simultaneous improvement of urethral histology could explain the functional change. By Masson's trichrome staining, we found that the striated muscle layer in rats of the exosome and ADSC groups were significantly thicker and denser than that of the SUI group. By HE staining, we demonstrated that no substantial immune response was induced around the injection site after 8-week injection of both hADSCs and exosomes. By immunofluorescence staining of FMHC and neurofilament 200 , we found that rats of the exosome and ADSC groups showed significantly higher density of striated muscle fibers and peripheral nerve fibers than that of the SUI group. The pattern of histological improvement was similar to that of functional change. On the other hand, the exosome group showed slightly better results than the ADSC group, and the difference was not significant. Accordingly, we could speculate that the exosome is the main effector of ADSCs, and a higher concentration of exosomes has a higher restorative effect for SUI.

The next question is how the exosomes benefit the recovery of SUI. In our study, we performed proteomic analysis using GO and KEGG pathway analyses. According to these results, ADSC-derived exosomes contained various proteins from a variety of pathways. Some of these proteins are associated with PI3K-Akt, Jak-STAT, and Wnt pathways that are related 
to skeletal muscle and nerve regeneration and proliferation. For instance, laminins critically contribute to cell attachment and differentiation, cell shape and movement, maintenance of tissue phenotype, and survival [39]. Reelin (RELN) is a large secreted extracellular matrix glycoprotein that helps regulate processes related to neuronal migration. Pigment epithelium-derived factor (PEDF) displays neurotrophic functions, and a previous study has reported that PEDF could protect against the neurogenic destruction of erectile function [40]. Therefore, these results support our hypothesis that the proteins contained in exosomes could effectively facilitate skeletal muscle and peripheral nerve regeneration by stimulating related signaling pathways.

To our knowledge, this study is the first in which SUI has been treated with exosomes and the first in which ADSC-derived exosomes were delivered into the pelvis and urethra. Stem cell-derived exosomes, as a cell-free therapy, have low immunogenic capacity and have no risks of infection, tumorigenicity, or thrombosis. Despite accumulating evidence of the therapeutic effects of exosomes, it remains unclear which factors in exosomes play key roles in controlling cell fate and promoting skeletal muscle and peripheral nerve regeneration. Further identification of the main molecules contained in exosomes that could facilitate the regeneration of skeletal muscle and peripheral nerves is required to elucidate the mechanisms underlying exosome-based therapeutics.

In conclusion, in the current research, we have demonstrated that rats receiving exosomes derived from ADSCs as a therapeutic strategy showed improved functional and histological recovery after SUI. More striated muscle fibers and peripheral nerve fibers were found in the urethra after exosome treatment. Proteomic analyses identified 1466 proteins, and some of these are associated with functions such as cell regeneration and migration. Thus, exosome treatment could be a new, clinically useful tool providing a cell-free therapeutic approach for treating SUI. However, future work will be necessary to confirm the implications and mechanisms.

\section{Abbreviations}

ADSC (adipose-derived stem cell); hADSC (human adipose-derived stem cell); SUI (stress urinary incontinence); CCK-8 (Cell Counting Kit-8); PNT (pudendal nerve transection); VD (vagina dilation); CMG (cystometrography); LPP (leak point pressure); BC (bladder capacity); DLS (dynamic light scattering ); SEM (scanning electron microscopy); GO (Gene Ontology); KEGG (Kyoto Encyclopedia of Genes and Genomes); FMHC (fast myosin heavy chain); EUS (external urethral sphincter); PEDF (pigment epithelium-derived factor).

\section{Acknowledgements}

This work was supported by the National Natural Science Foundation of China (No. 81370795).

\section{Disclosure Statement}

The authors declare that they have no competing interests. 


\section{Cellular Physiology Cell Physiol Biochem 2018;48:1710-1722 \begin{tabular}{l|l|l} 
and Biochemistry Published online: August 2, 2018 & $\begin{array}{l}\text { C) } 2018 \text { The Author(s). Published by S. Karger AG, Basel } \\
\text { www.karger.com/cpb }\end{array}$ \\
\hline
\end{tabular}}

$\mathrm{Ni}$ et al.: Therapeutic Potential of ADSC Exosomes in SUI

\section{References}

1 Elser DM, Mitchell GK, Miklos JR, Nickell KG, Cline K, Winkler H, Wells WG: Nonsurgical transurethral collagen denaturation for stress urinary incontinence in women: 18-month results from a prospective longterm study. Neurourol Urodyn 2010;29:1424-1428.

-2 Lemperle G, Lappin PB, Stone C, Lemperle SM: Urethral bulking with polymethylmethacrylate microspheres for stress urinary incontinence: tissue persistence and safety studies in miniswine. Urology 2011;77:1005.

-3 Haylen BT, de Ridder D, Freeman RM, Swift SE, Berghmans B, Lee J, Monga A, Petri E, Rizk DE, Sand PK, Schaer GN: An International Urogynecological Association (IUGA)/International Continence Society (ICS) joint report on the terminology for female pelvic floor dysfunction. Neurourol Urodyn 2010;29:4-20.

-4 Turco MP, de Souza AB, de Campos Sousa I, Fratini P, Veras MM, Rodrigues MN, de Bessa J, Jr., Brolio MP, Leite KR, Bruschini H, Srougi M, Miglino MA, Gomes CM: Periurethral muscle-derived mononuclear cell injection improves urethral sphincter restoration in rats. Neurourol Urodyn 2017;36:2011-2018.

5 Wan X, Liu C, Chen YB, Gu M, Cai ZK, Chen Q, Wang Z: Sulforaphane Treatment of Stress Urinary Incontinence Via the Nrf2-ARE Pathway in a Rat Model. Cell Physiol Biochem 2017;44:1912-1922.

6 Zhou S, Zhang K, Atala A, Khoury O, Murphy SV, Zhao W, Fu Q: Stem Cell Therapy for Treatment of Stress Urinary Incontinence: The Current Status and Challenges. Stem Cells Int 2016;2016:7060975.

7 Sadeghi Z, Isariyawongse J, Kavran M, Izgi K, Marini G, Molter J, Daneshgari F, Flask CA, Caplan A, Hijaz A: Mesenchymal stem cell therapy in a rat model of birth-trauma injury: functional improvements and biodistribution. Int Urogynecol J 2016;27:291-300.

-8 Gill BC, Sun DZ, Damaser MS: Stem Cells for Urinary Incontinence: Functional Differentiation or Cytokine Effects? Urology 2018;117:9-17.

-9 Li M, Li G, Lei H, Guan R, Yang B, Gao Z, Hui Y, Chen F, Xin Z: Therapeutic Potential of Adipose-derived Stem Cell-based Microtissues in a Rat Model of Stress Urinary Incontinence. Urology 2016;97:277.e271-277.e277.

$>10$ Zhao W, Zhang C, Jin C, Zhang Z, Kong D, Xu W, Xiu Y: Periurethral injection of autologous adipose-derived stem cells with controlled-release nerve growth factor for the treatment of stress urinary incontinence in a rat model. Eur Urol 2011;59:155-163.

-11 Kuismanen K, Sartoneva R, Haimi S, Mannerstrom B, Tomas E, Miettinen S, Nieminen K: Autologous adipose stem cells in treatment of female stress urinary incontinence: results of a pilot study. Stem Cells Transl Med 2014;3:936-941.

12 Wu J, Li J, Chen WK, Liu S, Liu JH, Zhang JS, Fang KW: MicroRNA-214 Affects Fibroblast Differentiation of Adipose-Derived Mesenchymal Stem Cells by Targeting Mitofusin-2 during Pelvic Floor Dysfunction in SD Rats with Birth Trauma. Cell Physiol Biochem 2017;42:1870-1887.

13 Mirotsou M, Jayawardena TM, Schmeckpeper J, Gnecchi M, Dzau VJ: Paracrine mechanisms of stem cell reparative and regenerative actions in the heart. J Mol Cell Cardiol 2011;50:280-289.

14 Herberts CA, Kwa MS, Hermsen HP: Risk factors in the development of stem cell therapy. J Transl Med 2011;9:29.

15 Kansu E: Thrombosis in stem cell transplantation. Hematology 2012;17 Suppl 1:S159-162.

16 Poulos J: The limited application of stem cells in medicine: a review. Stem Cell Res Ther 2018;9:1.

-17 De Jong OG, Van Balkom BW, Schiffelers RM, Bouten CV, Verhaar MC: Extracellular vesicles: potential roles in regenerative medicine. Front Immunol 2014;5:608.

-18 Burger D, Vinas JL, Akbari S, Dehak H, Knoll W, Gutsol A, Carter A, Touyz RM, Allan DS, Burns KD: Human endothelial colony-forming cells protect against acute kidney injury: role of exosomes. Am J Pathol 2015;185:2309-2323.

19 Xin H, Li Y, Chopp M: Exosomes/miRNAs as mediating cell-based therapy of stroke. Front Cell Neurosci 2014;8:377.

20 Li W, Liu Y, Zhang P, Tang Y, Zhou M, Jiang W, Zhang X, Wu G, Zhou Y: Tissue-Engineered Bone Immobilized with Human Adipose Stem Cells-Derived Exosomes Promotes Bone Regeneration. ACS Appl Mater Interfaces 2018;10:5240-5254.

21 Luo Q Guo D, Liu G, Chen G, Hang M, Jin M: Exosomes from MiR-126-Overexpressing Adscs Are Therapeutic in Relieving Acute Myocardial Ischaemic Injury. Cell Physiol Biochem 2017;44:2105-2116.

22 Choi EW, Seo MK, Woo EY, Kim SH, Park EJ, Kim S: Exosomes from human adipose-derived stem cells promote proliferation and migration of skin fibroblasts. Exp Dermatol 2017;10.1111/exd.13451 


\section{Cellular Physiology Cell Physiol Biochem 2018;48:1710-1722 \begin{tabular}{ll|l} 
DOI: 10.1159/000492298 & and Biochemistry Published online: August 2, 2018 & $\begin{array}{l}\text { O } 2018 \text { The Author(s). Published by S. Karger AG, Basel } \\
\text { www.karger.com/cpb }\end{array}$
\end{tabular}}

$\mathrm{Ni}$ et al.: Therapeutic Potential of ADSC Exosomes in SUI

-23 Otero-Ortega L, Gomez de Frutos MC, Laso-Garcia F, Rodriguez-Frutos B, Medina-Gutierrez E, Lopez JA, Vazquez J, Diez-Tejedor E, Gutierrez-Fernandez M: Exosomes promote restoration after an experimental animal model of intracerebral hemorrhage. J Cereb Blood Flow Metab 2018;38:767-779.

24 Shi R, Jin Y, Cao C, Han S, Shao X, Meng L, Cheng J, Zhang M, Zheng J, Xu J, Li M: Localization of human adiposederived stem cells and their effect in repair of diabetic foot ulcers in rats. Stem Cell Res Ther 2016;7:155.

25 Zhu Y, Wang Y, Zhao B, Niu X, Hu B, Li Q, Zhang J, Ding J, Chen Y, Wang Y: Comparison of exosomes secreted by induced pluripotent stem cell-derived mesenchymal stem cells and synovial membrane-derived mesenchymal stem cells for the treatment of osteoarthritis. Stem Cell Res Ther 2017;8:64.

-26 Cannon TW, Damaser MS: Effects of anesthesia on cystometry and leak point pressure of the female rat. Life Sci 2001;69:1193-1202.

-27 Peng CW, Chen JJ, Chang HY, de Groat WC, Cheng CL: External urethral sphincter activity in a rat model of pudendal nerve injury. Neurourol Urodyn 2006;25:388-396.

28 Hong SH, Piao S, Kim IG, Lee JY, Cho HJ, Kim SW, Hwang TK, Lee JY: Comparison of three types of stress urinary incontinence rat models: electrocauterization, pudendal denervation, and vaginal distension. Urology 2013;81:465.e461-466.

29 Gill BC, Damaser MS, Vasavada SP, Goldman HB: Stress incontinence in the era of regenerative medicine: reviewing the importance of the pudendal nerve. J Urol 2013;190:22-28.

-30 Pan HQ Kerns JM, Lin DL, Sypert D, Steward J, Hoover CR, Zaszczurynski P, Butler RS, Damaser MS: Dual simulated childbirth injury delays anatomic recovery. Am J Physiol Renal Physiol 2009;296:F277-283.

-31 Herrera-Imbroda B, Lara MF, Izeta A, Sievert KD, Hart ML: Stress urinary incontinence animal models as a tool to study cell-based regenerative therapies targeting the urethral sphincter. Adv Drug Deliv Rev 2015;8283:106-116.

-32 Williams JK, Dean A, Lankford S, Criswell T, Badlani G, Andersson KE: Determinates of muscle precursor cell therapy efficacy in a nonhuman primate model of intrinsic urinary sphincter deficiency. Stem Cell Res Ther 2017;8:1.

-33 Sugimura-Wakayama Y, Katagiri W, Osugi M, Kawai T, Ogata K, Sakaguchi K, Hibi H: Peripheral Nerve Regeneration by Secretomes of Stem Cells from Human Exfoliated Deciduous Teeth. Stem Cells Dev 2015;24:2687-2699.

-34 Doeppner TR, Herz J, Gorgens A, Schlechter J, Ludwig AK, Radtke S, de Miroschedji K, Horn PA, Giebel B, Hermann DM: Extracellular Vesicles Improve Post-Stroke Neuroregeneration and Prevent Postischemic Immunosuppression. Stem Cells Transl Med 2015;4:1131-1143.

35 Biancone L, Bruno S, Deregibus MC, Tetta C, Camussi G: Therapeutic potential of mesenchymal stem cellderived microvesicles. Nephrol Dial Transplant 2012;27:3037-3042.

- 36 Katsuda T, Kosaka N, Takeshita F, Ochiya T: The therapeutic potential of mesenchymal stem cell-derived extracellular vesicles. Proteomics 2013;13:1637-1653.

37 Nakamura Y, Miyaki S, Ishitobi H, Matsuyama S, Nakasa T, Kamei N, Akimoto T, Higashi Y, Ochi M: Mesenchymalstem-cell-derived exosomes accelerate skeletal muscle regeneration. FEBS Lett 2015;589:1257-1265.

-38 Lopez-Verrilli MA, Picou F, Court FA: Schwann cell-derived exosomes enhance axonal regeneration in the peripheral nervous system. Glia 2013;61:1795-1806.

39 Colognato H, Yurchenco PD: Form and function: the laminin family of heterotrimers. Dev Dyn 2000;218:213234.

40 Yang Q Chen X, Zheng T, Han D, Zhang H, Shi Y, Bian J, Sun X, Xia K, Liang X, Liu G, Zhang Y, Deng C: Transplantation of Human Urine-Derived Stem Cells Transfected With Pigment Epithelium-Derived Factor to Protect Erectile Function in a Rat Model of Cavernous Nerve Injury. Cell Transplant 2016;25:1987-2001. 